\title{
Lapurdum
}

Euskal ikerketen aldizkaria | Revue d'études basques |

Revista de estudios vascos | Basque studies review

Numéro spécial 4 | 2019

SACAZE bildumako euskal testuak (1887)

\section{J. Sacazeren gutuna herrietako errientei}

\section{Gotzon Aurrekoetxea, Charles Videgain et Aitor Iglesias Chaves}

\section{(2) OpenEdition \\ Journals}

\section{Édition électronique}

URL : https://journals.openedition.org/lapurdum/2893

DOI : 10.4000/lapurdum.2893

ISSN : 1965-0655

\section{Éditeur}

IKER

Édition imprimée

Date de publication : 1 octobre 2019

Pagination : 33-34

ISBN : 9782955341339

ISSN : $1273-3830$

\section{Référence électronique}

Gotzon Aurrekoetxea, Charles Videgain eta Aitor Iglesias Chaves, «J. Sacazeren gutuna herrietako errientei», Lapurdum [Linean], Numéro spécial 4 | 2019, Sarean emana----an 12 janvier 2020, kontsultatu 22 septembre 2022. URL: http://journals.openedition.org/lapurdum/2893 ; DOI: https:// doi.org/10.4000/lapurdum.2893

\section{(c) (i) $\odot$}

Creative Commons - Attribution-NonCommercial-NoDerivatives 4.0 International - CC BY-NC-ND 4.0 https://creativecommons.org/licenses/by-nc-nd/4.0/ 


\title{
3. J. SACAZEREN GUTUNA HERRIETAKO ERRIENTEI
}

\author{
VILLE DE TOULOUSE
}

Exposition Universelle de 1887

SOUS LE PATRONAGE DE L'ÉTAT

SECTION PYRÉNÉENNE

\section{GÉOGRAPHIE HISTORIQUE DES PYRÉNÉES VIIe PARTIE LINGUISTIQUE ET TOPONYMIE}

MONSIEUR L'INSTITUTEUR,

La ville de Toulouse et mes collègues du Comité de la section pyrénéenne m'ont appelé à l'honneur d'organiser l'exposition spéciale de la Géographie historique des Pyrénées.

Mon intention n'est pas de réunir une quantité considérable d'objets dont la vue hâtive ne laisse au visiteur que le souvenir d'une curiosité plus ou moins satisfaite ; je voudrais travailler surtout à l'avancement de la science française et réaliser, dans la mesure de mes forces, une ouvre utile et durable. Pour cela, il a fallu dégager ma tâche de ce qu'elle avait de trop complexe et concentrer mes efforts sur quelques parties essentielles, les plus intéressantes, d'ailleurs.

La linguistique a tout d'abord attiré mon attention. Il importe, en effet, de recueillir sur nos vieux idiomes pyrénéens des documents qu'il sera bientôt impossible de se procurer. Chaque jour la langue française, l'une des forces les plus expansives de notre nation, bat en brèche les patois romans et le basque lui-même, et l'on peut prévoir le temps où ces anciens idiomes seront tellement altérés qu'il y aura lieu d'en souhaiter la complète disparition.

Pour conserver un monument de notre langue populaire et aussi pour fournir aux linguistes des éléments d'étude et de comparaison, j’ai eu la pensée de faire noter par MM. les Instituteurs un spécimen de l'idiome local dans chacune des communes qui composent les huit départements de la région pyrénéenne (Pyrénées-Orientales, Aude, Ariège, Haute-Garonne, Gers, 
Hautes-Pyrénées, Basses-Pyrénées et Landes). Je viens donc vous prier, Monsieur l'Instituteur, de traduire en patois et en basque, selon l'idiome qui se parle dans la commune que vous habitez, les deux textes suivants : «La légende de Barbazan et la légende de Tantugou ».

Il existe dans les idiomes du Midi une infinité de sons que le français ne possède pas et, pour rendre ces sons, on n'a point établi un système unique de transcription. Votre œuvre n'aura donc de valeur que si elle est traitée avec un soin minutieux. Ecrivez les mots tels qu'il se prononcent et n'oubliez pas un seul instant que c'est l'idiome de votre commune, et non celui d'une localité plus ou moins rapprochée, que vous devez recueillir. Des collaborateurs intelligents, nés dans la commune - les vieillards, de préférence, - vous faciliteront la tâche : vous écrirez sous leur dictée, vous leur lirez et relirez votre travail, avant de le transcrire sur cette feuille, et vous aurez à cour, je n'en doute point, d'approcher le plus possible de la perfection. Les matériaux ainsi rassemblés serviront à une étude comparée des idiomes pyrénéens (basque, gascon, languedocien, catalan) et nous permettront de classer les dialectes, les sous-dialectes et jusqu'aux variétés dialectales modernes qui se manifestent souvent entre des localités toutes voisines.

La seconde partie du travail comprend la liste des noms topographiques et la carte de votre commune, d'après le plan cadastral et les divers documents que vous pourrez utiliser. S'il est possible, tous les noms portés dans la liste devront se trouver aussi dans la carte ; si la place fait défaut, vous mettrez les noms les plus importants, les plus anciens, les plus caractéristiques. Ces «noms de lieux », dont vous reverrez soigneusement l'orthographe, présentent un grand intérêt, non seulement au point de vue géographique, mais au point de vue de la linguistique et de l'ethnologie elle-même.

Toutes les feuilles reliées en plusieurs volumes formeront un recueil très précieux qui sera déposé, après la clôture de l'Exposition, dans la Bibliothèque publique de la ville de Toulouse, où les hommes d'étude l'auront toujours à leur disposition.

Veuillez agréer, Monsieur l'Instituteur, l'expression de mes meilleurs sentiments.

JULIEN SACAZE,

Correspondant du Ministère de l'Instruction Publique. Saint-Gaudens, le 17 février 1887

Nous recommandons de la manière la plus pressante à MM. les Instituteurs l'œuvre entreprise par M. Julien SACAZE, et nous les invitons à remplir avec un soin extrême la mission qui leur est confiée. Nous adressons, à cet effet, des instructions spéciales à MM. les inspecteurs d'Académie et à MM. les Inspecteurs primaires.

Le Recteur

de l'Académie de Toulouse

Cl. PERROUD
Le Recteur

de l'Académie de Bordeaux

H. OUVRÉ
Le Recteur

de l'Académie de Montpellier

G. CHANCEL 